\title{
NEUROLOGICAL DETERIORATION AFTER POSTERIOR WIRING OF THE CERVICAL SPINE
}

\author{
DOUGLAS W. LUNDY, H. HERNDON MURRAY
}

From the Shepherd Center, Atlanta, USA

Posterior cervical wiring is commonly performed for patients with spinal instability, but has inherent risks. We report eight patients who had neurological deterioration after sublaminar or spinous process wiring of the cervical spine; four had complete injuries of the spinal cord, one had residual leg spasticity and three recovered after transient injuries.

We found no relation between the degree of spinal canal encroachment and the severity of the spinal-cord injury, but in all cases neurological worsening appeared to have been caused by either sublaminar wiring or spinous process wiring which had been placed too far anteriorly.

Sublaminar wiring has substantial risks and should be used only at atlantoaxial level, and then only after adequate reduction. Fluoroscopic guidance should be used when placing spinous process wires especially when the posterior spinal anatomy is abnormal.

J Bone Joint Surg [Br] 1997;79-B:948-51.

Received 23 December 1996; Accepted after revision 16 July 1997

Wiring of an unstable cervical spine was first reported by Hadra in 1891, and numerous methods have been described including sublaminar, spinous process, tension band, facet and triple wiring. Neurological complications have been reported but are considered to be rare. ${ }^{2-6}$ Some recent articles have reported the significant risk inherent in the use of sublaminar wires. $3,7,8$

At our regional spinal injury rehabilitation centre, we see many patients with cervical spinal injuries and quadriplegia. Since 1984, we have treated eight patients who sustained neurological injury during posterior cervical fixation with wire at other hospitals. We report the details, potential

D. W. Lundy, MD, Resident, Georgia Baptist Medical Centre H. H. Murray, MD, Attending, Shepherd Centre

4934 Lakeside Drive, Atlanta, Georgia 30360, USA.

Correspondence should be sent to Dr H. H. Murray at 2001 Peachtree Street NE, Suite 400, Atlanta, Georgia 30309, USA

(C)1997 British Editorial Society of Bone and Joint Surgery 0301-620X/97/67923\$2.00 risks and causes of neurological deterioration, and make recommendations to reduce the risk.

\section{PATIENTS AND METHODS}

All eight patients had been referred to our institution for evaluation and rehabilitation. In a retrospective review, we studied their medical records and all available radiographs and MRI and CT scans to assess any compromise of the spinal canal by the wires or in any other way. We used the classification system of Geremia et $\mathrm{al}^{4}$ to evaluate the degree of canal compromise (Table I). For patients treated by sublaminar wiring, we measured encroachment of the wire into the spinal canal on the lateral radiograph. For those treated by spinous process wiring, we assessed the extent of encroachment on axial CT scans.

Five of the patients had had sublaminar wiring and three spinous process wiring. Their mean age was 37 years (13 to 68). Six had been treated for traumatic instability, one for instability due to a hypoplastic odontoid and one for a painful pseudarthrosis after the failure of an anterior cervical discectomy and fusion for degenerative disc disease.

\section{RESULTS}

Five of the patients were neurologically intact or had very minor signs before the original operation. One had complete quadriplegia at the C5 level and two had incomplete quadriplegia (Table II). After surgery, all eight patients had developed new neurological deficits. Four had complete quadriplegia at a more cephalad level; three of them needed ventilator support, and all four remained unchanged after rehabilitation, although one was eventually weaned from the ventilator. Three had nearly complete resolution of their neurological injury, and one continued to have residual

Table I. Classification of canal encroachment by posterior wires $\left(\right.$ Geremia et $\left.\mathrm{al}^{4}\right)$

\begin{tabular}{|c|c|}
\hline Gra & \\
\hline I & Anterior bowing into the posterior $25 \%$ of the spinal canal \\
\hline II & Anterior bowing into the posterior $26 \%$ to $50 \%$ \\
\hline III & $\begin{array}{l}\text { Bowing beyond the midline of the canal but not into the } \\
\text { anterior } 25 \%\end{array}$ \\
\hline IV & Bowing into the anterior $25 \%$ \\
\hline
\end{tabular}

THE JOURNAL OF BONE AND JOINT SURGERY 
Table II. Neurological status of eight patients with deterioration after wiring

\begin{tabular}{lllllll}
\hline \multicolumn{1}{c}{ Case } & Level & Pathology & Operation* & Preop & Postop & Eventual \\
\hline 1 & C5 to C6 & Subluxation & SL & Intact & C6 ASIA A & C6 ASIA A \\
2 & C5 & Burst fracture & SL & C5 ASIA A & C3 ASIA A - ventilator & C3 ASIA A - ventilator \\
3 & C2 & Hypoplastic odontoid & SL & Intact & C3 ASIA A - ventilator & C3 ASIA A - ventilator \\
4 & C1 to C2 & Subluxation & SL & Intact & Right hemiparesis & Right leg spasticity \\
5 & C4 to C5 & Subluxation & SL & C4 ASIA D & C4 ASIA C & Intact \\
6 & C6 to C7 & Bilateral facet dislocation & SP & Intact & C6 & Intact \\
7 & C5 to C6 & Subluxation & SP & C6 ASIA B & C4 ASIA A - ventilator & C5 ASIA A \\
8 & C4 to C5 & Failed ACDF $\dagger$ & SP & Intact & C5 ASIA D & Intact \\
\hline
\end{tabular}

* SL, sublaminar; SP, spinous process

$\dagger$ anterior cervical discectomy and fusion

spasticity of the right leg.

Three of the five patients treated by sublaminar wires had adequate postoperative radiographs and these showed grade-II encroachment into the canal. Two of the patients treated by spinous process wires had grade-I encroachment. We found no apparent correlation between the degree of encroachment and the neurological deficit. The cause of the encroachments and injuries varied. Two of the patients with sublaminar wires did not have adequate reduction of the cervical spine before surgery, and the other three may have been injured by anterior bowing of the wires. In all three patients with spinous process wiring, the wire had been placed anterior to the spinolaminar line and within the spinal canal, probably traumatising the spinal cord during its passage.

\section{Sublaminar wires}

Case 1. A 60-year-old man sustained C5 to C6 subluxation in a motor-vehicle accident, and had no neurological signs. He was treated in traction and after six days had a posterior cervical fusion with sublaminar wiring. After this, he developed complete sensory paraplegia at the T3 level. At operation the wires were removed, a laminectomy was performed and C5 to C6 spinous process wiring applied. After this operation he became completely quadriplegic at C6 and did not improve.

Case 2. A 15-year-old youth had a C5 burst fracture and C5 complete quadriplegia in a diving accident. After two days in traction he had sublaminar wiring and fusion from $\mathrm{C} 4$ to C7 (Fig. 1). In the recovery room he had developed C3 complete, ventilator-dependent quadriplegia and radiographs showed grade-II encroachment of $42 \%$ into the canal. No further surgery was performed, and there was no improvement.

Case 3. A 53-year-old woman, neurologically intact, had $\mathrm{C} 1$ to $\mathrm{C} 2$ sublaminar wiring and fusion for a hypoplastic odontoid and subluxation. The wires were passed without adequate reduction and could not be properly placed. No wires were left in situ, but when she woke, she was ventilator-dependent with complete C3 quadriplegia and did not improve.

Case 4. A 13-year-old boy with Down's syndrome sustained $\mathrm{C} 1$ to $\mathrm{C} 2$ subluxation with normal neurological status. Traction and $\mathrm{C} 1$ to $\mathrm{C} 2$ sublaminar wiring with fusion were performed on the same day. He developed a right-sided hemiparesis; postoperative radiographs showed anterior bowing of the sublaminar wires with $28 \%$ encroachment. The wires were removed and fusion from the occiput to $\mathrm{C} 3$ performed. There was almost full neurological recovery but some residual spasticity of one leg.

Case 5. A 21-year-old man sustained a $\mathrm{C} 4$ to $\mathrm{C} 5$ subluxation in a fall at gymnastics. The original dense quadriplegia quickly improved to C4 ASIA (American Spinal Injury Association) D quadriplegia. Seven days after the injury, sublaminar wiring and fusion from $\mathrm{C} 4$ to $\mathrm{C} 5$ led to increased left-sided weakness but eventually recovered to nearly normal neurological function. Postoperative radiographs showed grade-II encroachment of $39 \%$ into the canal.

\section{Spinous process wires}

Case 6. A 68-year-old woman fell from a bed and sustained

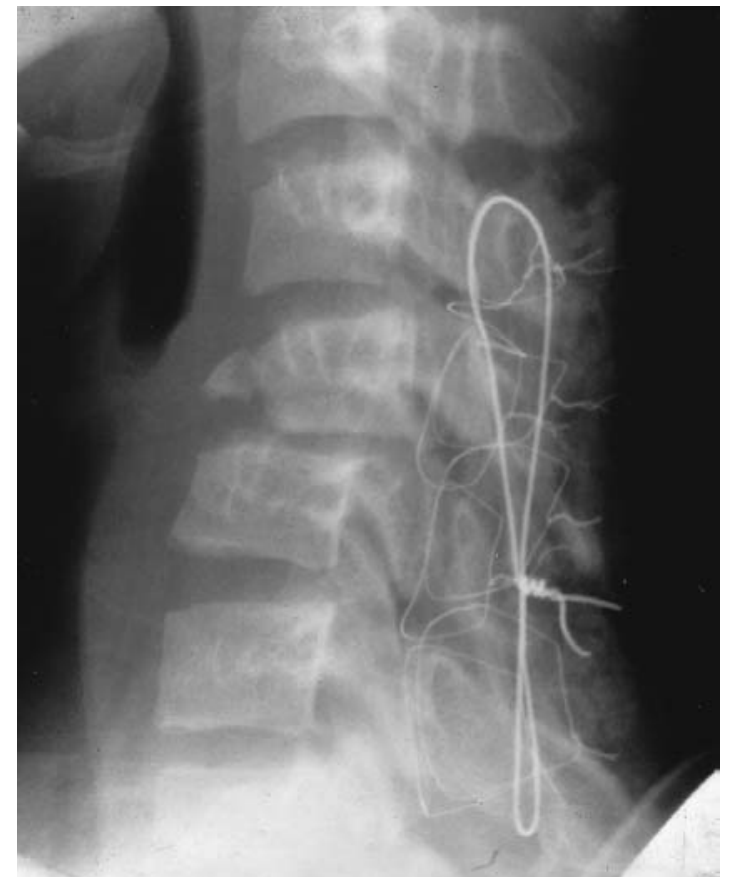

Fig. 1

Lateral radiograph after sublaminar wiring. Multiple wires had been passed at several levels. 

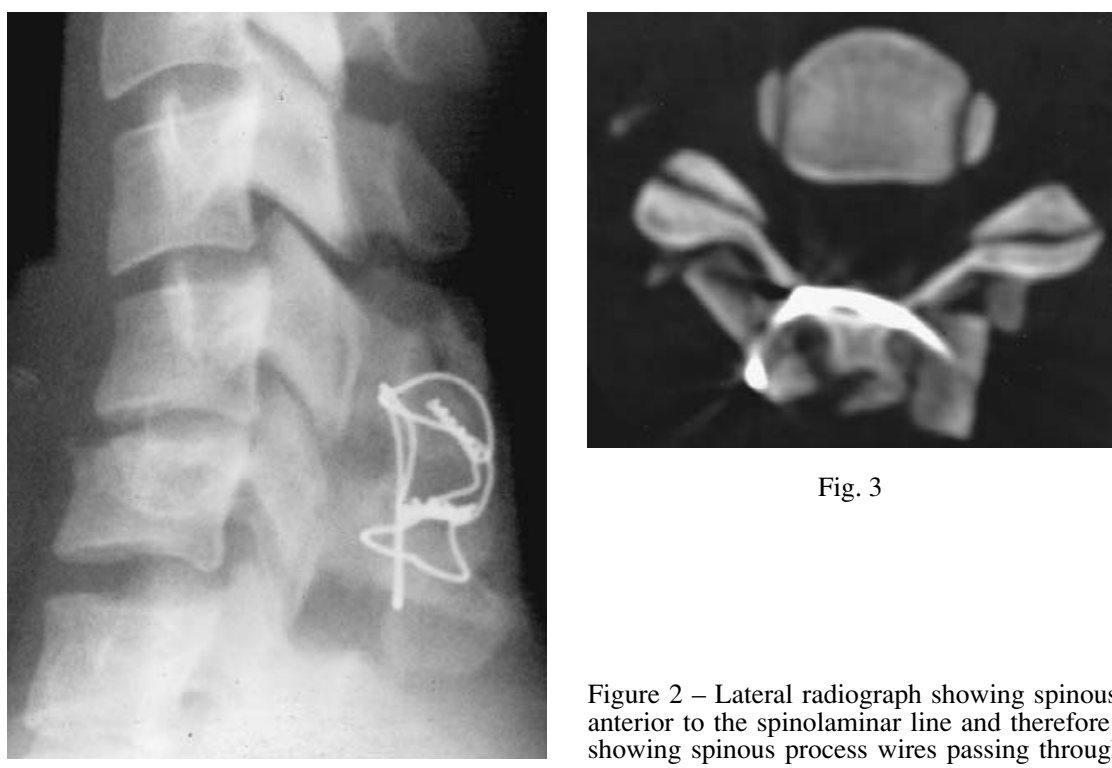

Fig. 3

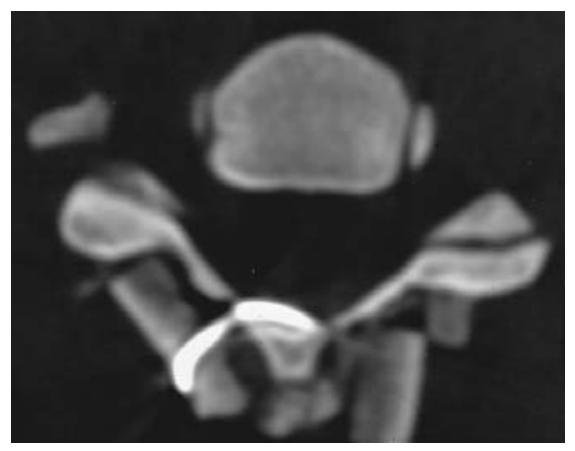

Fig. 4

Fig. 2

bilateral facet dislocation of C6 on C7. She was initially assessed as neurologically intact except for a weak right triceps and decreased rectal tone. Traction and attempts at closed reduction were unsuccessful. Open reduction and wiring of the spinous processes of $\mathrm{C} 6$ to $\mathrm{C} 7$ and fusion resulted in incomplete quadriplegia requiring ventilator support. Conservative management gave gradual improvement to C6 ASIA D quadriplegia, and at discharge she had only mild numbness in her hands and legs. Postoperative radiographs and CT showed encroachment of the wire by $2 \mathrm{~mm}$ into the posterior canal (grade I).

Case 7. A 22-year-old man sustained a hyperextension injury at rugby football. He had C5 to C6 perched facets and C6 ASIA B quadriplegia. After traction for three days he had C5 to C6 spinous process wiring and fusion (Figs 2 to 4). He awoke with complete, ventilator-dependent $\mathrm{C} 4$ quadriplegia. Postoperative CT scans showed C5 and C6 wires penetrating by $4 \mathrm{~mm}$ and $3 \mathrm{~mm}$ (grade I). No further surgery was performed and he improved to a C5 complete quadriplegic, and was weaned from the ventilator.

Case 8. A 47-year-old man, neurologically intact, had persistent neck pain after failed anterior cervical discectomy and fusion for a degenerative disc at C4/C5. The pseudarthrosis was treated by $\mathrm{C} 4$ to $\mathrm{C} 5$ spinous process wiring and fusion. The patient developed C5 ASIA D quadriplegia and postoperative CT showed wire in the spinal canal at $\mathrm{C} 4$. The wires were immediately removed at operation, a laminectomy was performed and a posterior cerclage wire placed. There was gradual improvement, eventually leaving only minimal left-sided arm and leg weakness.

\section{DISCUSSION}

Most surgeons now advise against the use of sublaminar wires in the cervical spine. Bohlman ${ }^{9}$ cites the risks of radiculopathy and cord compression, and considers that spinous process wiring is safer. Meyer ${ }^{5}$ abandoned the use of sublaminar wires after two patients had sustained neurological deterioration. Geremia et $\mathrm{al}^{4}$ reported neurological complications in three of 42 patients (7\%) after sublaminar wiring, and Wilber et $\mathrm{al}^{10}$ found a $17 \%$ incidence of neurological symptoms associated with sublaminar wires, noting that even in asymptomatic patients, neurological changes could be recorded by spinal cord monitoring by somatosensory cortically evoked potentials. Schrader, Bethem and Scerbin ${ }^{11}$ also expressed reservations about sublaminar wiring after studying the chronic, local effects of wires in dogs, and Coe et $\mathrm{al}^{7}$ found no biomechanical advantage of such wires as against other techniques.

Sublaminar wires are still used at the atlantoaxial level, although there are some concerns. Smith et al $^{6}$ noted a high incidence of complications in a series of 47 patients with sublaminar wiring of the upper cervical spine. There are individual case reports of a broken sublaminar cable or wire penetrating the spinal cord in the upper cervical spine, and Fraser et al, ${ }^{3}$ despite the proven efficacy of sublaminar wires in the upper spine, advised other means of fixation. Goll et al ${ }^{12}$ recommend the avoidance of the lateral passage of the wire and careful prebending before placement.

Several authors consider that there is an increased risk of neurological injury when wires are passed under more than one lamina at a time. Geremia et $\mathrm{al}^{4}$ noted the increased risk of anterior bowing of a wire, and both of Meyer's patients with neurological damage had wires passed under three laminae. ${ }^{5}$ Watts, Smith and Knoller ${ }^{13}$ reviewed 34 patients without neurological damage and considered that sublaminar wiring is safe if limited to one or two laminae. Our review has shown that sublaminar wiring can be dangerous even at one level.

We have abandoned the use of sublaminar cervical wir- 
ing $^{4,5}$ in the subaxial spine unless unusual circumstances preclude other options. We continue to use them at the atlantoaxial level, where there is more anatomical canal space $^{14}$ and there are inadequate spinous processes. Below $\mathrm{C} 2$, we consider that there is too little margin for error.

Some recent articles have cited the advantages of stranded cables over solid wires for cervical stabilisation. Songer et $\mathrm{al}^{15}$ found that stainless-steel cables were strong and flexible with a greater tendency to conform to the lamina while Huhn et al ${ }^{8}$ confirmed their strength and flexibility.

Spinous process wiring, in contrast to sublaminar passage, is widely considered to be quite safe since no wires should be introduced into the spinal canal. We have found no previous reports of neurological injury from this procedure. Hadra, in his pioneering 1891 report, ${ }^{1}$ described "the wiring of the sixth and seventh spinous process with silver wire, carrying it four to five times around in a figure of eight". Numerous variations and refinements of the technique have since appeared, ${ }^{9,16-19}$ and Rogers, ${ }^{16}$ seeking to eliminate the problem of wire slippage, introduced the method of placing a small transverse hole in the base of the spinous process of each vertebra through which the wire is placed before and after wrapping it around the process. The three patients whom we report had neurological injuries resulting from technical errors in Rogers-type wiring. Injuries appeared to have occurred when the holes were placed too far anteriorly, and the wires were unknowingly introduced into the spinal canal. It may be quite easy to make the hole through the posterior lamina instead of the spinous process in vertebrae with no obvious transition from the lamina to the spinous process. We now use lateral fluoroscopy when placing these holes: in an ideal lateral view the spinolaminar line clearly shows the posterior boundary of the canal, and care should be taken to stay posterior to this level.

Our cases highlight the important role of modern imaging techniques in the treatment of cervical trauma. Preoperative images help the surgeon to determine if techniques of posterior cervical wiring are appropriate, based on the stability of the posterior elements. Axial CT images show the morphology of the spinous processes. When neurological injury is diagnosed after posterior cervical wiring, MRI and contrast CT can now show with much greater precision whether wires are compressing the spinal cord. Neurologically-incomplete postoperative deficits, with a recognised neuropathy, should be fully investigated as soon as possible with the aim of relieving compression. In one reported case ${ }^{4}$ of incomplete quadriplegia after sublaminar wiring, removal of the wires, although delayed, resulted in an excellent recovery.

\section{Conclusions}

1) During cervical traction to reduce a deformity, the patient should be conscious so that neurological problems at that stage can be recognised.

2) During spinous process wiring, lateral imaging should ensure that the holes and wires are posterior to the spinolaminar line.

3) Sublaminar wiring of the subaxial spine should be used only when there is no acceptable alternative. At the atlantoaxial level, reduction must be complete before wires are passed.

4) Neurological deterioration after posterior wiring requires immediate imaging studies to exclude any compressive lesion and to allow early surgical revision when this is indicated.

We wish to thank Brian Bell for his assistance with this manuscript.

No benefits in any form have been received or will be received from a commercial party related directly or indirectly to the subject of this article.

\section{REFERENCES}

1. Hadra BE. The classic-wiring of the vertebrae as a means of immobilization in fracture and Potts' disease. Clin Orthop 1975; 112:4-8.

2. Blacklock JB. Fracture of a sublaminar stainless steel cable in the upper cervical spine with neurological injury: case report. J Neurosurg 1994;81:932-3.

3. Fraser AB, Sen C, Casden AM, Catalano PJ, Post KD. Cervical transdural intramedullary migration of a sublaminar wire: a complication of cervical fixation. Spine 1994;19:456-9.

4. Geremia GK, Kim KS, Cerullo L, Calenoff L. Complications of sublaminar wiring. Surg Neurol 1985;23:629-35.

5. Meyer PR. Cervical spine fractures: changing management concepts. In: Bridwell KH, DeWald RL, eds. Textbook of spinal surgery. Vol. 2. Philadephia: J.B. Lippincott Company, 1991:1001-80.

6. Smith MD, Phillips WA, Hensinger RN. Complications of fusion to the upper cervical spine. Spine 1991;16:702-5.

7. Coe JD, Warden KE, Sutterlin CE, McAfee PC. Biomechanical evaluation of cervical spinal stabilization methods in a human cadaveric model. Spine 1989;14:1122-31.

8. Huhn SL, Wolf AL, Ecklund J. Posterior spinal osteosynthesis for cervical fracture/dislocation using a flexible multistrand cable system: technical note. Neurosurgery 1991;21:943-6.

9. Bohlman H. Surgical management of cervical spine fractures and dislocations In: AAOS Instructional Course Lectures. Vol. 34, Illinois: 1985:163-87.

10. Wilber RG, Thompson GH, Shaffer JW, Brown RH, Nash CL Jr. Postoperative neurological deficits in segmental spinal instrumentation: a study using spinal cord monitoring. J Bone Joint Surg [Am] 1984;66-A:1178-87.

11. Schrader WC, Bethem D, Scerbin V. The chronic local effects of sublaminar wires: an animal model. Spine 1988;13:499-502.

12. Goll SR, Balderston RA, Stambough JL, et al. Depth of intraspinal wire penetration during passage of sublaminar wires. Spine 1988; 13:503-9.

13. Watts C, Smith H, Knoller N. Risks and cost-effectiveness of sublaminar wiring in posterior fusion of cervical spine trauma. Surg Neurol 1993;40:457-60.

14. Cooper PR. Stabilization of fractures and subluxations of the lower cervical spine. In: Cooper PR, ed. Management of post-traumatic spinal instability. Park Ridge, Illinois: American Assocation of Neurological Surgeons, 1990:11-33.

15. Songer MN, Spencer DL, Meyer PR, Jayaraman G. The use of sublaminar cables to replace Luque wires. Spine 1991;16:Suppl 8: 418-21.

16. Rogers WA. Treatment of fracture-dislocation of the cervical spine. $J$ Bone Joint Surg 1942;24:245-58.

17. Segal D, Whitelaw GP, Gumbs V, Pick RY. Tension band fixation of acute cervical spine fractures. Clin Orthop 1981;159:211-22.

18. Schlicke LH, Schulak DJ. Wiring of the cervical spinous process. Clin Orthop 1981;154:319-20.

19. Weiland DJ, McAfee PC. Posterior cervical fusion with triple-wire strut graft technique: one hundred consecutive patients. J Spinal Disord 1991;4:15-21. 